\title{
Enhanced Student Learning Experience in Technical Drawing and CAD through Augmented Reality and Micro-credentials
}

\section{Dr. Jeff Hung, State University of New York, Farmingdale}

Dr. Yue (Jeff) Hung holds degrees in engineering and technology disciplines (Ph.D. in Materials Science and Engineering, M.S in Mechanical Engineering, and B.S in Manufacturing Engineering Technology). He has over 20 years' experience in Computer-Aided Design (CAD) applications. His areas of expertise also include Computer-Aided Manufacturing (CAM), Computer Number Control (CNC), new product development, fuel cell technology, and Vanadium Redox Flow Battery (VRFB) technology. He is currently the Chair and associate professor of the Mechanical Engineering Technology Department at Farmingdale State College.

\section{Mr. Daniel Weinman, State University of New York, Farmingdale}

Mr. Daniel Weinman earned his M.S. degree in Mechanical Engineering from Stony Brook University and his B.S. degree in Mechanical Engineering Technology from Farmingdale State College. Presently, he is an Adjunct Instructor in addition to being the Instructional Support Specialist of the Mechanical Engineering Technology Department at Farmingdale State College. Mr. Weinman has been teaching in the areas of manufacturing processes, Computer Numerical Control machining, and Computer-Aided Design (CAD). 


\title{
Enhanced Student Learning Experience in Technical Drawing and CAD through Augmented Reality and Micro Credentials
}

\author{
Yue (Jeff) Hung', Daniel Weinman ${ }^{1}$ \\ 1 Farmingdale State College
}

\begin{abstract}
Computer Aided Drafting and Design is a required freshman course for Mechanical Engineering Technology AAS and BS and Manufacturing Engineering Technology BS programs at Farmingdale State College. The course teaches students technical drawings and computer aided design (CAD) which includes 2D computer aided drafting, and 3D modeling. These topics are closely related. The students who excel in these topics will have a much higher marketability than others because most mechanical design jobs in industry require the knowledge of technical drawings and CAD. In addition, the students must know these topics before they continue in the programs.

The instructors of this course have observed that students typically struggle with technical drawings when they are required to visualize 2D orthographic views of a 3D object and visualize a 3D model from a 2D technical drawing. Traditionally, large physical demonstration models are used to demonstrate the teaching materials to the entire class. The models are cumbersome, and it is not practical to carry a variety of models for each student. As a result of this, students are forced to share the models which limits the time they have with the physical models and tends to negatively affect student learning. This traditional teaching method poses a major challenge particularly to students with learning disabilities who require extra time to learn the materials.

Since this is a freshman course, teaching materials should be widely available to the freshman students to encourage them to review the course materials and ensure their success in the course in order for them to move forward to other courses. Accordingly, new demonstration models through augmented reality (AR) are proposed to enhance student learning in technical drawing and CAD. Micro credentials such as digital badges are also proposed to motivate students to achieve better than just a passing grade and further improve their marketability. This paper discusses the development of the new teaching tools and micro credentials.
\end{abstract}

\section{Introduction}

Technical drawings are essential in mechanical and manufacturing engineering technology fields. They serve as important communication tools for engineers. The drawings provide basic guidelines for design ideas and details. They also act like an extremely useful agreement between designers, engineers, and manufacturers $[1,2]$. For example, a mechanical engineer indicates all the design specifications of a product such as size, shape, and materials in drawings so that a manufacturing engineer can produce this product accordingly. Many commercial and residential 
products such as copy machines, computers, televisions, phones, cars, shampoo bottles, garden hoses, and more, are mass produced. These products must have their own design specifications for mass production. In many cases, these products are designed and manufactured by a group of engineers. The engineers will need to use drawings to convey their designs and specifications to each other. Therefore, they must be able to create, read, and understand technical drawings.

Technical drawing is often the first introductory course for mechanical and manufacturing engineering technology programs in many academic institutions. Since personal computers and computer aided design (CAD) software are widely available, technical drawing is often taught with CAD systems. As technical drawing and CAD are important topics in engineering, many educators around the globe have shared various teaching methods or improvements in these areas not only to enhance the student learning experience in technical drawing and CAD related topics but also to help with retaining students in the STEM field. For example, Cayiroglu [3] developed a new method for machining feature extracting of objects using $2 \mathrm{D}$ technical drawings. The method is used to determine the negative features which will be processed on the orthographic views of the parts. Altuger-Genc et al. [4] developed two approaches to provide freshman engineering technology students an applied learning experience in technical drawings and CAD. The first approach involves hands-on exercises that follow Bloom's Revised Taxonomy and the second approach is a learning community that is focusing on the Computer Aided Drafting and Design and Manufacturing Processes courses.

At Farmingdale State College, Computer Aided Drafting and Design (CADD) is a required freshman course for Mechanical Engineering Technology AAS and BS and Manufacturing Engineering Technology BS programs. It is a 3-credit and 4-contact hour course. The course consists of a lecture component and a laboratory component. In the lecture component, the instructor introduces the class materials to the students. The students will then practice their CADD skills in the laboratory component. The course teaches students technical drawings, 2D computer aided drafting, and 3D modeling. These topics are closely related. The course is essential for engineering technology students because most mechanical design jobs in industry require the knowledge of technical drawings and CAD. Students must know these topics before they continue in their programs. The topics are the prerequisite of many technology courses such as advanced manufacturing, quality control, and computer aided manufacturing where students are required to understand and analyze technical drawings properly. During the first seven weeks of the semester, the course focuses on technical drawing and 2D AutoCAD. In the remaining eight weeks of the semester, the course focuses on 3D modeling using Autodesk Inventor. Two textbooks, Technical Drawing with AutoCAD [5] and 101 Autodesk Inventor 2017 [6], are used in this course.

The authors are the main instructors of the CADD course in the state college. They have observed that students usually face difficulties visualizing 2D orthographic views of an object and visualizing a 3D model from a 2D technical drawing. Similar observations were reported by Serdar et al. [7]. The group also investigated the effects of spatial visualization ability in academic performance in engineering. Their study shows that spatial visualization skills 
positively affect student learning. The authors of this paper have also observed students sometimes will get confused on the pictorial drawings that are assigned for 3D modeling. The students made mistakes in 3D modeling not because of their 3D modeling skills but because of the misinterpretation of the drawings. In the CADD course, the authors usually use large physical models to demonstrate the teaching materials to the entire class. However, the models are cumbersome. It is not practical to carry a variety of models for each student. When the students are required to share the models, they will have limited time on the models to understand the teaching materials. This traditional teaching method poses a major challenge to students with learning disabilities who need extra time to learn the materials. The availability of teaching materials will have a positive impact on student success in the course.

In this work, new augmented reality (AR) demonstration models were developed to enhance student learning. Students in the CADD course will learn technical drawings with the assistance of the AR models. This paper discusses the development of the models, how the models are intergraded in the class, how the new teaching method is assessed, and the future plans of the project. This paper also discusses the development of micro credentials such as micro certificates or digital badges in Computer Aided Design (CAD).

\section{Development of augmented reality models}

Augmented reality is a new technology that has quickly become popular in the entertainment industry. For example, the augmented reality game "Pokémon Go" successfully demonstrated the utilization of the technology in the game industry. The result of this application has been remarkable. Additionally, augmented reality is widely used in educational research. Kim et al. [8] proposed and implemented an augmented reality-based drawing verification system. The system utilizes both marker and markerless recognition methods for efficient operation. Their study suggested that the system can improve the understanding of drawings and will be more useful for railway construction which consists of a combination of heterogeneous drawings. Also, Serdar [9] developed mixed reality tools in an engineering drawing course. The tools enable students to visualize geometry problems and enhance their spatial visualization skills.

In this project, student exercises from the textbooks were selected for AR model development. These AR models require 3D models of the exercises and target/scan images. These images can be either two-dimensional barcode (QR codes) or images of the exercises. Autodesk Inventor was used to create the $3 \mathrm{D}$ models. The models were then imported into the AR environments using ENTiTi by WakingApp, an Autodesk partner. The images of the exercises were used as the target images. Students can use the ENTiTi mobile viewer to view the AR models on their mobile devices. This setup provided students with the full access to the demonstration models at any time. Figure 1 shows an example of the AR model on the textbook. Since the 3D models were available in the AR environment, students could access the digital models anytime in the class room or at home when they face difficulty in visualizing the orthographic views in the exercises. They do not have to share the models. The AR models also provide clear presentation 
of the exercises to avoid misinterpretation of the drawings. The new teaching tools allowed the students to experience the limitations and advantages of the AR technology at the same time.
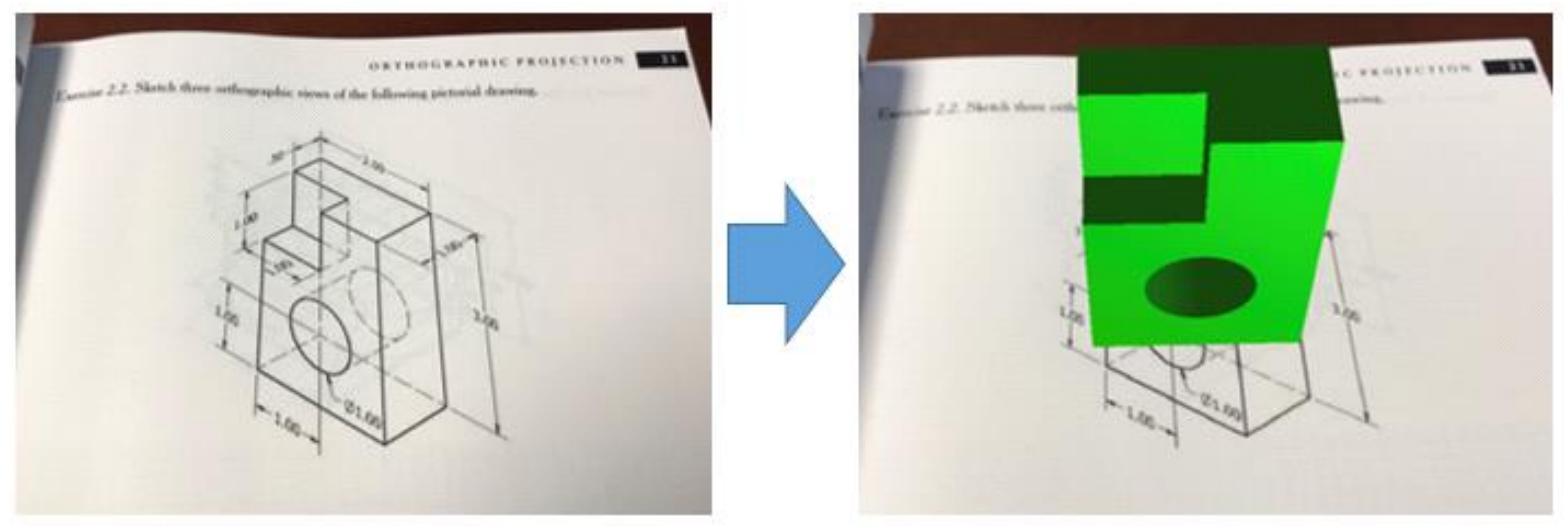

Figure 1: AR model of a class exercise from the technical drawing textbook ${ }^{5}$

\section{Development of micro credential in CAD}

One of the goals in this project is to introduce a micro credential such as micro certificates or digital badges to the students. Micro credential is a small-scale award system for demonstrating some competency in a particular area. This type of award system motivates students to perform better in their classes. Positive results, including better grades have been reported [10-12].

Digital badge was chosen in this project as the method of delivering the micro credential. The college has just begun evaluating the implementation and requirements of digital badges. In an effort to develop a digital badge in CAD, the authors consulted with the industry advisory committee in the Fall 2018. The function of the committee is to recommend the department the most current industry requirements and provide guidance to the department on its programs. It also helps the department continually improve its programs and more importantly ensure that the department is preparing its students properly for the field. The advisory committee members indicated that they would prefer students who are not only proficient in CAD software but also knowledgeable in manufacturing. The main reason is that they would want the students to be able to design or create components that are not only functional but also manufacturable. Based on the comments from the industry advisors, four tentative CAD and manufacturing related courses were proposed as the requirement of the digital badge in CAD. This new digital badge proposal will be presented to the industry advisory committee in the Spring 2019. Once the department and the committee finalize the course details, the proposal will be submitted to the college for final approval. The course descriptions of the tentative CAD and manufacturing courses are as follows: 


\section{Technical Drawing and CAD}

This is a laboratory course designed to provide students with hands-on experience in technical drawing and computer aided design (CAD). Students will apply traditional drafting techniques, such as orthographic projection, dimensioning, and tolerancing, through 2D CAD software.

\section{Solid modeling}

In this course, students will learn 3D solid modeling based on parametric constraints, dimensions, and features such as extrude, revolve, sweep, loft, hole, fillet and shell. The course also teaches students how to create assemblies and 2D technical drawings from 3D models. Laboratory exercises will be assigned to the students for hands-on experience with the related topics.

\section{Manufacturing processes}

The main purpose of this course is to introduce the mechanical engineering technology students to the principles and operation of mechanical equipment such as lathes, drill press, milling machines, measuring requirements, and measuring instruments. Several manufacturing processes such as welding, powder metallurgy, sheet metal forming, extrusion, etc. are also covered. Individual laboratory projects will be assigned to each student to reinforce the topics covered in the theory.

\section{Advanced solid modeling}

This is an advance 3D modeling course. The topics include sheet metal, welding, mold design, design configurations, and design for manufacturing. The students are required to complete a term project where they will apply their knowledge in 3D modeling and manufacturing.

\section{Assessment plan}

Student grades in the CADD course will be used to evaluate the effectiveness of the AR demonstration models. Four semesters of student grades prior to Fall 2018 semester will be used as the control group. The sample size is 78 . The students in the control group were taught with the traditional teaching method which utilized physical demonstration models.

Students who took the CADD course in or after Fall 2018 were introduced to the new teaching tools. The student grades from the Fall 2018 and beyond will be used as the enhanced group and compared to those of the control group to study the effectiveness of the new teaching tools. The class averages of the orthographic projection related exams and course grades between the two

groups will be compared. Since there were only 13 students in the Fall 2018 class, the data was inconclusive due to the low sample size of the enhanced group.

However, student opinions about the new teaching tools were collected in the Fall 2018 group. Student surveys indicated that $70 \%$ of the students feel the AR models helped them learn orthographic projection. The remaining $30 \%$ did not feel the AR models were helpful because some of these students thought that the AR models were not user friendly and some of them did 
not have the right hardware and software. Also, some of them already had prior knowledge of technical drawings. They were able to complete the exercises without the help of AR models.

\section{Conclusions and future work}

This paper reviews the development of AR demonstration models and digital badges in CAD for the Mechanical Engineering Technology Department at Farmingdale State College. The AR demonstration models were implemented during the Fall 2018 semester. Since the student data was collected from a small population, student grades in the future semesters will be collected to make a more comprehensive evaluation.

The courses required for the digital badge in CAD were proposed and will be discussed with the industry advisory committee in Spring 2019. The digital badge can certainly support adult learners who already have an engineering degree or the background knowledge in engineering but lack of the knowledge in CAD. They do not have to take the entire degree in order to show the competency in CAD. Also, it will help employers to identify suitable candidates who have a competency in CAD. Since the college has just begun evaluating digital badges, the authors will wait for the implementation and structure of digital badges at the college level. Upon implementation, this digital badge in CAD will be one of the first badges for the college.

\section{Acknowledgement}

The authors would like to thank the SUNY Innovative Instruction Technology Grant (IITG) program for supporting this project.

\section{References}

[1] Theodore J. Branoff, Modris Dobelis, "Engineering Graphics Literacy: Spatial Visualization Ability and Students' Ability To Model Objects from Assembly Drawing Information", Proceedings of the 2012 ASEE Annual Conference \& Exposition, June 10-13, 2012, San Antonio, Texas

[2] Yamei Wen, Hui Zhang, Jiaguang Sun, Jean-Claude Paul, "A new method for identifying and validating features from 2D sectional views", Computer-Aided Design 2011; 43: 677-686

[3] Ibrahim Cayiroglu, "A new method for machining feature extracting of objects using 2D technical drawings", Computer-Aided Design 2009; 41: 1008-1019

[4] Gonca Altuger-Genc, Yue (Jeff) Hung, Daniel Weinman, "Enhancing Freshman Learning Experience in Computer Aided Drafting and Design (CADD) Through Applied Learning Experiences: Connecting the Dots", Proceedings of the 2017 Mid-Atlantic ASEE Fall Conference, October 6-7, Penn State Berks, PA

[5] Jeff Hung, “Technical Drawing with AutoCAD, $2^{\text {nd }}$ edition”, Linus Learning, 2018 
[6] Jeff Hung, “101 Autodesk Inventor 2017”, Linus Learning, 2016

[7] Tumkor Serdar, Roelof Harm DeVries, "Enhancing Spatial Visualization Skills in Engineering Drawing Course", Proceedings of the 2015 ASEE Annual Conference \& Exposition, June 14-17, 2015, Seattle, WA

[8] Hyeoun-Seong Kim, Sangmi-Park, Sunju-Han, Leen-Seok Kang, "AR-based 4D CAD system using marker and markerless recognition method", Procedia Engineering 2017; 196: $29-35$

[9] Tumkor Serdar, "Mixed Reality Tools in Engineering Drawing Course", Proceedings of the 2016 ASEE Annual Conference \& Exposition, June 26-29, 2016, New Orleans, LA

[10] Michael Fosmire, Amy S. Van Epps, Nastasha E Johnson, "Badging Your Way to Information Literacy", Proceedings of the 2015 ASEE Annual Conference \& Exposition, June 14-17, 2015, Seattle, WA

[11] Rob van Roy, Sebastian Deterding, Bieke Zaman, "Collecting Pokémon or receiving rewards? How people functionalise badges in gamified online learning environments in the wild", International Journal of Human-Computer Studies 2018; In Press

[12] Timna Garnett, Didy Button, "The use of digital badges by undergraduate nursing students: A three-year study", Nurse Education in Practice 2018; 32: 1-8 